\title{
The 2011 Census taking shape: methodological and technological developments
}

Ian White

Office for National Statistics

As reported in Population Trends $135^{1}$ the UK Statistics Authority's proposals for the next Census in England and Wales, to be taken in March 2011, were published and presented to Parliament and the National Assembly for Wales in a Government White Paper $^{2}$ on 11 December.

This article - the second of two to report on the significant recent developments in the design of the Census - summarises the key methodological, operational and technological changes that have been introduced since the 2001 Census, with the prime aim of achieving, and reporting on, the most accurate estimate of the resident population.

\section{The decision on the 2011 Census}

As reported in Population Trends $135^{1}$ the next Census of Population is scheduled to be taken in England and Wales on Sunday 27 March 2011. Censuses will also be taken on the same day in Scotland and Northern Ireland subject to separate legislative procedures in the Scottish Parliament and the Northern Ireland Assembly. The 2011 Census will be the twenty-first in a series carried out every 10 years in England and Wales since 1801, except in 1941.

Government, local authorities, the health service, the education and academic community, commercial business, professional organisations and the public at large all need reliable information on the number and characteristics of people and households if they are to conduct many of their activities effectively. This need is currently best met by conducting a census every ten years covering the whole of the population, and by updating the population estimates each year benchmarked on the preceding Census.

Taking account of the many comments, evaluations and recommendations arising from the 2001 Census, the design of the 2011 Census is based on a number of key strategic aims:

- to give the highest priority to getting the national and local population counts right

- to maximise overall response and minimise differences in response rates in specific areas and among particular population sub-groups

- to build effective partnerships with other organisations, particularly local authorities, in planning and executing the field operation

- to provide high quality, value-for-money, fit-for-purpose statistics that meet user needs and which are as consistent, comparable and accessible across the UK as is possible; and 
- to protect, and be seen to protect, confidential personal census information.

\section{Collecting the information: the field operation}

The data collection operation is always the public face of the census and covers a wide range of activities in addition to delivering the questionnaires and collecting the completed returns. These include field force recruitment, legal, financial and technological issues, and contractual arrangements with suppliers. For the 2001 Census, more focus was given to the data collection activities, compared with previous censuses, since it had to count a population that was undergoing greater societal change. This strategic approach is again being followed for the 2011 Census.

Experience has shown that it is increasingly difficult to make contact with households, especially (but not exclusively) in inner cities. This has been a major influence in shaping data collection plans for the 2011 Census. These difficulties can be attributed to: an ageing population; growing numbers of one-person households; changing work patterns; increase in access security control systems; numbers of recent migrants, particularly from Eastern Europe; and certain groups and communities within the population feeling increasingly disconnected with society. Ensuring that every household gets a Census questionnaire (the term 'Census form' is used interchangeably in this article) and is motivated to fill it in is, therefore, more than ever a key driver in the strategy and planning for data collection.

The 2011 Census will be conducted in a way that is primarily designed to achieve completeness of coverage with an efficient use of resources while, at the same time, maintaining the public's acceptance and confidence in the importance and security of the Census. Although many aspects of the Census will follow well-established and proven methodologies, ONS has introduced changes to improve the efficiency of the census operation and provide better help to the public.

A number of key objectives of the data collection operation underpin the broad strategic aims of the Census; these are to:

- develop an effective enumeration methodology that targets resources and procedures to maximise response

- track delivery and receipt of the census forms to target non-response

- encourage a high level of online response (which has the potential to reduce costs in other areas)

- overcome the problems associated with the recruitment, retention and payment of a large field force

- manage public participation and co-operation through informative publicity; and

- work with local authorities and others in planning and executing the enumeration, in particular to make best use of their knowledge of local addresses and residence arrangements and ways of contacting hard-to-count groups.

\section{Recruitment, training and payment of field force}

The strategy for the recruitment, training and payment of the large, temporary Census field force will be somewhat different for 2011 to that followed in 2001 and previous censuses. The early outsourcing of these services to a contractor with particular expertise in field operations is in response to the concerns set out in the National Audit Office's report to the Public Accounts Committee on Outsourcing the 2001 Census $^{3}$. Such services, to this scale, are clearly a non-core activity for ONS and cannot be provided internally without a significant additional investment.

ONS worked successfully with a contracted supplier to deliver the provision of field staff recruitment, training and payment in the 2007
Census Test, with the result that it decided to outsource these services for the 2011 Census. Though responsibility for field recruitment will rest with the supplier, ONS intends that the staff appointed for the field operation should to some degree reflect the profile of the communities within which they will be working. Not only is this a necessary stance in terms of ensuring equal opportunities but it will also enable field staff to engage more effectively with the local communities they are enumerating, encourage participation, and understand the support required. This includes, for example, ensuring that sufficient numbers of Welsh-speaking field staff are recruited in different parts of Wales to ensure that the Census there is conducted effectively and in compliance with ONS's obligations under the provisions of the Welsh Language Act.

ONS announced in March this year that Capita would be the supplier of these services for the 2011 Census. The statutory obligation for persons employed on the Census to adhere to strict confidentiality undertakings will apply equally to all field staff recruited in this way as they would to any permanent Census staff at ONS.

\section{Posting out census questionnaires and developing an address register}

Following the successful trialling of post-out as a delivery mechanism for census questionnaires in the 2007 Census Test $^{4}$, the decision was to adopt this methodology as the prime means of form delivery for the 2011 Census. The rationale for adopting this strategy is that even with hand delivery in the 2001 Census, enumerators failed to make doorstep contact with households at more than a third of addresses and resorted to delivering the form through the letter box. The use of an established postal service provider to perform this activity will enable field resources to be directed to those areas where a more focused approach to follow-up activities is necessary in order to improve response rates. ONS expects to post out Census questionnaires to as many as 95 per cent of households - with the remaining 5 per cent being delivered by field staff in the more traditional manner in areas to be determined by factors associated with:

- confidence in the accuracy of the address list in any given area

- the proportion of known, or suspected, multi-occupied properties in the area

- concentrations of large households; and

- a reduction in the general postal service provision where it is anticipated that there would be significant proportions of households to whom a questionnaire might not be successfully delivered by mail.

For the 2009 Rehearsal the addresses where there will be hand delivery will be selected at the geographic level of Lower Layer Super Output Areas (LSOA) containing around 600 households. However, it may be the case that this will be too large an area to be sufficiently selective in the Census itself and would negate some of benefits of seeking to focus follow-up staff in areas of particularly low response. In which case, the delivery method would be determined at the Enumeration District level.

Following a competitive tender for the post-out service, the Royal Mail has been appointed.

The use of a postal service provider for the delivery (and also the return of forms - see below) will help overcome the difficulties of recruiting large numbers of temporary enumerators to deliver questionnaires to every address, and of accessing accommodation protected by security systems. Together with the option of making a return online (see below), this will free-up field staff to be more flexibly deployed wherever necessary. There will be continuous monitoring of the progress of the enumeration in the field so that extra assistance can be quickly redirected to wherever necessary. 
Clearly the pre-requisite for a successful post-out strategy is the availability of a comprehensive, high quality address register for all areas of England and Wales. In the absence of a single authoritative source of national address information, ONS is developing an address register that meets Census requirements in terms of quality and coverage, and which local authorities can be confident will effectively underpin the Census enumeration and subsequent outputs. Full use will be made of the primary sources of address lists, namely the Royal Mail's Postcode Address File (PAF), and the National Land and Property Gazetteer (NLPG), which is administered by the Information Development Agency (IDeA) through the Local Government Information House (LGIH). Data derived from the Valuation Office records will be used to help improve matching rates.

The resulting register will contain a list of addresses linked to higher level geographic areas for management, reporting and output purposes. This will require associating every address with an accurate positional reference, provided by the Ordnance Survey, both for planning field operations including the printing of forms and production of outputs.

Research is ongoing to refine the technical approach to developing and maintaining the address register, and more detailed plans for this will be announced over the coming months.

\section{Address checking}

To ensure the Census address list is as complete and up-to date as possible address checks will be carried out by field staff in those areas where there is the greatest uncertainty about the quality of address lists - currently expected to cover up to 30 per cent of the country subject to the results of further research. The check prior to the 2007 Census Test, for example, revealed that an additional 11,700 or more households (equivalent to around 11 per cent of those residential addresses on the original list) within the sampled areas that were not on the Register at that time. These tended to be at multi-occupied addresses where houses had been converted into flats.

A pilot exercise was conducted in July-September 2008 in 27 local authorities in England and Wales to test key elements of the address register design and the methods for updating it. There were three main stages of activity:

(a) matching of the PAF and the NLPG

(b) investigation of unresolved addresses from matching by sending these addresses to the address product suppliers for initial evaluation with the residual addresses being passed to their respective local authorities for investigation; and

(c) field checking by ONS across parts of 16 of the pilot local authority sites to quality assure the pilot address register and identify missing or new addresses.

The pilot excluded the assessment of communal establishments which has a separate phase of research and development.

Where the matching of addresses was not resolved, this resulted mainly from differences in the naming and numbering and classification of properties within sub-divided buildings and grouped/linked buildings, for example, flats above shops and residential complexes, or where addresses in one address product did not match any addresses in the other, such as unclassified properties and addresses that may be unique to one product.

Feedback from the suppliers early on in the pilot indicated that many of the unresolved addresses were valid. The main contributing factors to these addresses not matching were the differences between the products arising from a lack of synchronisation between the update and the maintenance processes, and/or differences in naming and numbering conventions between national address products. Plans for the further development of the address register will take account of these issues.

The matching process was applied as separate exercises to May and August 2008 addresses products and achieved equivalent match rates. A further independent match conducted by suppliers within the Bristol City Council area corroborated the level of matching achieved by ONS Together these results indicate that the ONS matching process is robust and capable of providing repeatable and high quality results.

Unresolved addresses from matching were sent to address product suppliers and local authorities for investigation and resolution. The high rate of address resolution achieved by suppliers demonstrates the effectiveness of adopting an inclusive, collaborative approach, which will help reduce the burden on local authorities.

The local authorities themselves also actively engaged with the pilot in a number of ways. Almost all (25 out of the 27), took part in the pilot seminars and regional workshops organised by ONS to facilitate the address resolution process, and the majority (19) were also able to directly participate in address checking and investigation of unresolved addresses. Engagement with the network of regional chairs of the Local Land and Property Gazetteer (LLPG) meant that ONS was able to involve a total of more than 200 local authorities in the project.

The results of the pilot matching and fieldwork, and a discussion of how these will be used to inform future plans, will be published during the summer 2009.

To ensure that this preparation for the Census achieves a permanent improvement in existing address lists, it is intended that information on updates to the address list - arising, for example, from new housing development and any changes of status of existing addresses - will be shared with those organisations managing the PAF and NLPG, where such information does not disclose any personal census information. To this end, ONS has successfully signed up the main address list providers to an information sharing agreement.

\section{Returning census information online}

The option of two principal response routes will be available to enable the public to complete their census questionnaire either on the printed form and posting this back, or by online completion for the first time in the UK. There will, additionally, be special arrangements for the collection of completed returns from communal establishments such as universities and old people's homes.

It is not proposed to have any areas specifically designated for doorstep collection (as will be the case for hand-delivery), though householders unable to make a return by post or online may, instead, request a doorstep collection. Field staff at the follow-up stage will seek to collect Census questionnaires but this will only be at addresses from which a form has not been returned. Special assistance will be available to anyone who has difficulty in completing the Census questionnaire, particularly through language or infirmity. Field staff speaking both English and other languages and/or signers will be employed, where possible.

It is estimated from international census experience that up to 25 per cent of households will respond online, equating to, potentially, over 5 million responses altogether in England and Wales. ONS will therefore offer the option making a census return online; this facility will also be available for the censuses in Scotland and Northern Ireland. However, the actual take up of this channel is uncertain and the capacity planning for the response system must allow for flexibility. Such a facility will afford the possibility of both encouraging response among particular sub-groups of the population who may otherwise be hard to reach, and of 
achieving some data processing cost savings if overall response levels are sufficiently high. Furthermore, such an option meets the Government's aim of seeking to increase the provision of public services online, and will provide ONS with an opportunity to assess the efficacy of collecting information in such a way for any future censuses and other statistical surveys.

The online questionnaire will have the same question set as the paper form, but will allow for up to a maximum of 30 household members and visitors. There will be no unnecessary changes in the content - in order to minimise modal response bias - but a number of changes in the design will be required. These will include: dropdown menus of response categories for particular questions; the automatic filtering of those questions that are not required of every person (such as the employment questions); and the automatic population of certain fields from the responses given in others. In particular, the format of the relationship matrix (showing the inter-relationships of each person in the household - see Figure 1) will be affected in this way in an attempt to make the online version easier to complete.

Individual online returns will also be possible for use by households who choose to complete the household questionnaire on paper but may wish to use the Internet to include additional household members who cannot be accommodated on the paper form, or to allow an individual household member to make a return online separately from the rest of the household's return.
ONS will ensure that the online questionnaire is accessible to everyone, including those who require assistive technologies when using the Internet. All households will, however, receive a paper questionnaire whether or not they choose to make their return online. There will be no facility to enable a householder to pre-register an intention to do so as the risk of failure to make a return is considered to be too high. Instead, a unique Internet access code reference on each paper questionnaire will allow the secure access and completion of an online return. Linking this reference to the household will enable ONS to identify any duplication of paper and online returns. The address may also be checked at the start of the completion process to confirm identification. The form-tracking system will be updated whenever an online questionnaire has been submitted and a completion code given to the respondent.

\section{Special enumeration procedures for students and other hard-to-reach population groups}

One of the biggest challenges to overcome in the 2011 Census will be reaching population groups that are traditionally undercounted the so-called 'hard to count'. The strategies developed to enumerate households and communal establishments will clearly not be successful for everyone, and it is recognised that additional procedures will have to be adopted for hard-to-count populations. These groups will include, among others, students, people with no settled place of residence, such as Gypsies, and persons sleeping rough. Further analysis and changing social conditions may yet identify new populations beyond the

Name of Person 1
First name
\begin{tabular}{|l}
\hline Last name \\
ENTER NAME OF \\
PERSON 1 HERE AS \\
IN QUESTION H3
\end{tabular}

Name of Person 2
First name
How is Person 2 related
to Person:
Husband or wife
Same-sex civil
partner
Partner
Son or daughter
Step-child
Brother or sister
Step-brother or
step-sister
Mother or father
Step-mother or
step-father
Grandchild
Grandparent
Relation - other
Unrelated
(including foster child)

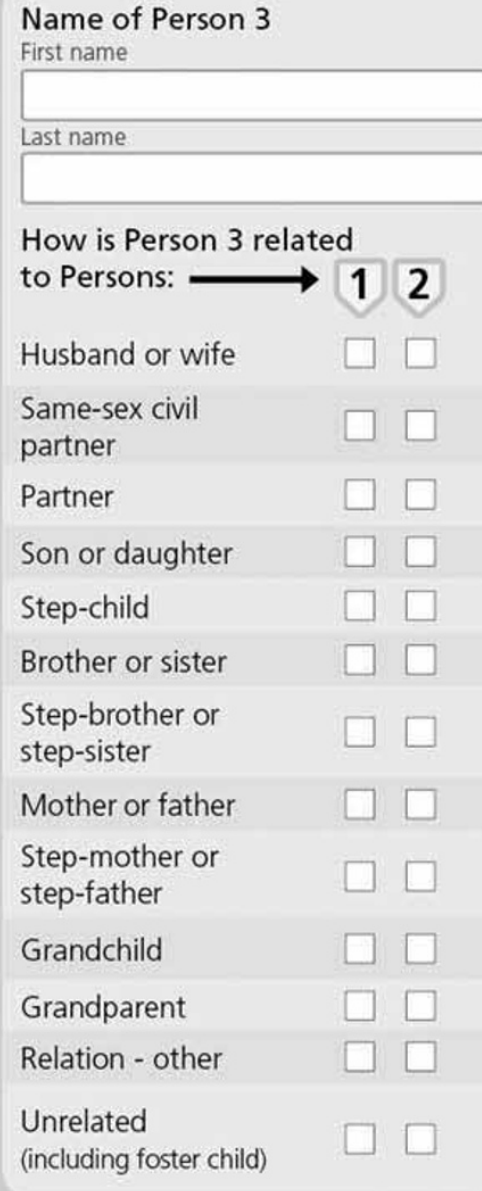


traditional groups, such as asylum seekers and refugees for whom special enumeration strategies will be necessary.

In addition there are other identifiable groups, dispersed throughout the population, who will require modified enumeration procedures. These include, but are not limited to:

- those unable to understand the census questionnaire, such as non-English speakers (and those in Wales who are also non-Welsh speakers) and people with reading difficulties

- those likely to have difficulty completing or returning a standard paper questionnaire, including the visually impaired or physically disabled; and

- those able, but unwilling, to complete a questionnaire.

Continued research and consultation with representative organisations through the Local Authority and Community Liaison Programmes (see below) will inform development of the most effective strategies to target and accommodate these groups, with the aim of ensuring that no community or individual is disenfranchised. In response to the recommendations in the Treasury Select Committee's report on the 2001 Census ${ }^{5}$ particular arrangements will be made to enable blind or partially sighted people and non-English speakers/non-Welsh speakers in Wales to make a census return. This includes the provision, on request, of a copy of the Census questions and the accompanying explanatory material in:

- Braille, large print and audio/visual formats; and

- 34 or more foreign language versions (see below).

The facility for Census returns to be made online (see above) will also enable translations of the questionnaire to be accessible to persons whose first language may not be English and/or who may be visually impaired.

Because the 2011 Census falls within the Easter vacation for some universities and other educational establishments, but in term-time for a number of others, special arrangements are being developed to ensure that all students (a notoriously difficult sub-group of the population to enumerate at the best of times) will receive, and be given every opportunity to return, a census questionnaire. These are likely to include the earlier delivery of questionnaires to those universities whose vacation dates are significantly earlier than elsewhere (such as Oxford and Cambridge) and to encourage an online response from whatever address they may happen to be present at on Census night. Particular attention will be given to such establishments in the follow-up phase in order to maximise response.

\section{Local authority and community liaison}

Research into the types of people missed in the 2001 Census and changing demographic profiles has helped to inform other initiatives needed to ensure coverage of the hard to count groups. The Local Authority and Community Liaison Programmes are key components of this research. The 2011 Census is building on the valuable experience gained and the lessons learned from the 2001 Census by placing emphasis on more collaboration with local authorities and with the many agencies and community organisations involved.

The best partners in working with ONS to maximise coverage are local authorities, whose need for reliable local information provides a strong incentive to assist in identifying and reaching local hard-tocount populations. By positively engaging local authorities in the development and quality assurance of address lists, for example, and actively encouraging them to promote the benefits of the Census in their areas, ONS is seeking to improve coverage. Such initiatives aim to cover not only the known disadvantaged groups, such as the disabled, ethnic minorities and very elderly, but will allow ONS to target resources at areas known to have the characteristics associated with poor coverage.
ONS wish to benefit from local authority resources and knowledge of their local areas to improve the enumeration process, and local authorities in turn will benefit from better census results. The most efficient way for Census field staff to make use of existing local networks has been explored with local authorities in preparing for both the 2007 Census Test and the Census Rehearsal in 2009. Agreed areas for partnership working include:

- identifying hard-to-count populations through local and community intelligence

- developing and endorsing up-to-date address lists

- $\quad$ assisting in field staff recruitment

- providing logistical support, such as local office accommodation

- promotion and publicity; and

- evaluation.

It is important for ONS to receive local authority buy-in to the 2011 Census enumeration strategy, especially so at the Chief Executive level, so that potential for disagreement and lack of confidence in the quality of final results can be minimised. ONS have persuaded Chief Executives of local authorities of the benefit of appointing Regional Census Champions from among the pool of Chief Executives that serve as Regional Returning Officers for European and General Elections, so that they may encourage and facilitate the appointment of Local Authority liaison managers to work with senior census staff to help shape the local enumeration.

The innovative 2001 Census Community Liaison Programme has been further developed to establish contact with relevant community groups and agencies. In response to the Treasury Select Committee's recommendations ${ }^{5}$ this Programme was initiated much earlier in the planning cycle (in 2006). Specific objectives of the 2011 Programme are to:

- encourage participation in the Census by publicising the Census and underline its use and value

- help provide a potential source of field staff; and

- provide help and guidance to local communities and individual members of the public.

The Census Diversity Advisory Group (one of two new Advisory Groups formed as part of the consultation arrangements for the 2011 Census) has also provided a forum to offer valuable advice and guidance on liaising with local communities and key organisations such as the Equality and Human Rights Commission, Age Concern, the Inter-Faith Network, the Royal National Institute for the Blind, the National Centre for Languages and others. In addition, ONS has established bilateral links with these and other related organisations and umbrella groups representing minority populations and special interest groups.

\section{Publicity}

While every household and each resident in a communal establishment in England and Wales is obliged by law to make a Census return, it would be impossible to carry out a Census without the co-operation of the public. ONS will, in close co-operation with the Census Offices in Scotland and Northern Ireland, arrange publicity to explain the purpose and value of the Census, to encourage householders to return completed questionnaires and to ensure that they know when and how to do so, to give assurances about confidentiality and data security, and to deal with other particular matters of public concern as and when they may arise. Reminders about the legal requirement to complete the Census will be promoted.

A Census brand with the slogan 'Help tomorrow take shape' (Figure 2) was launched in November 2008 to be the identifiable face of the Census to the general public, and will be adopted at every appropriate 


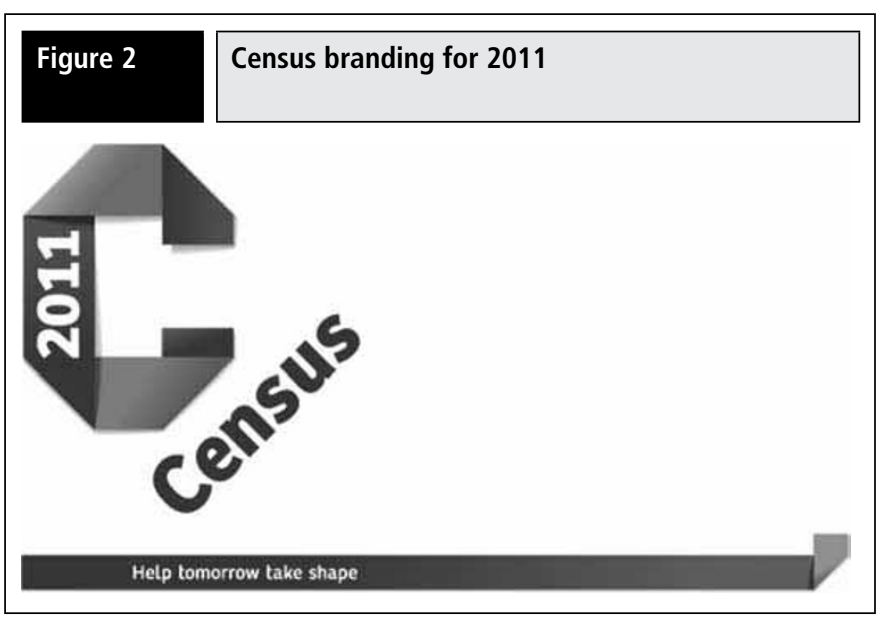

opportunity. The brand will be used to promote awareness of the 2009 Census Rehearsal in the selected areas in Lancaster, Newham and Ynys Môn -Isle of Anglesey.

The basis of good public relations will be to make sure that field staff are briefed and trained to be as helpful as possible where they are required to deliver census forms and collect completed returns, and that there is informative liaison with local community groups. The prime objectives of a phased national and local publicity campaign will be to:

- educate - by increasing the awareness and understanding about the 2011 Census among the general public, in key geographic areas and in hard-to-count groups

- enlist - by publicising and supporting the recruitment of field staff from public and key community groups, and informing the public, particularly in hard-to count areas and among hard-to-count groups that they will be required to participate

- engage - by publicising and supporting the delivery, completion and return of Census forms from the general public and hard-to-count groups, and giving clear assurances about confidentiality and security

- $\quad$ enforce - by ensuring that as many people as possible, from all population groups, are aware of the legal obligations to complete and return their Census questionnaires; and

- explain the results and promote the value of the 2011 Census.

Such publicity will be sought through a paid-for campaign, employing a contracted agency (Brayleino was appointed in March 2009 after an open competition), and through the co-operation of those stakeholders with particular vested interests in seeing a successful Census, such as local authorities.

An explanatory leaflet will be delivered with each census form, and publicity will increase as Census Day approaches. The Contact Centre, providing a telephone help-line with foreign language interpreters, will be available to answer queries from the public prior to and during the Census. In addition a Census Help website will be provided during both the Rehearsal and Census operational periods.

The questionnaire for Wales will be available for completion in either English or Welsh, with translations as well as other help and supporting information available bilingually via the Census Help facility. Translations of the census questions into 34 or more foreign languages in England and Wales will also be available online to assist respondents whose first language is not English or Welsh. Languages in which such translations will be available are likely to include those shown in Box One. These are the languages that will be recognised in the 2009 Census Rehearsal (including two additional languages in Northern Ireland) but more will be added for the Census itself.

\section{Box one}

\section{Languages into which the 2011 Census questions and supporting material are likely to be translated}

$\begin{array}{lll}\text { Akan Twi-Fante } & \text { Irish (N Ireland only) } & \text { Russian } \\ \text { Arabic } & \text { Italian } & \text { Shqip/Albanian } \\ \text { Bengali } & \text { Kurdish Sorani } & \text { Slovak } \\ \text { Bulgarian } & \text { Latvian } & \text { Somali } \\ \text { Cantonese } & \text { Lithuania } & \text { Spanish } \\ \text { Czech } & \text { Malayalam } & \text { Tagalog/Filipino } \\ \text { Farsi/Persian } & \text { Mandarin } & \text { Tamil } \\ \text { French } & \text { Polish } & \text { Tigrinya } \\ \text { German } & \text { Portuguese } & \text { Turkish } \\ \text { Gujarati } & \text { Punjabi Gurmukhi } & \text { Ulster Scots (N Ireland only) } \\ \text { Hindi } & \text { Punjabi Shahmukhi } & \text { Urdu } \\ \text { Hungarian } & \text { Romanian } & \text { Yoruba }\end{array}$

\section{Outsourcing parts of the census operation}

ONS is outsourcing some of its 2011 Census activities and processes to external suppliers. This is not a new strategy; the Census has traditionally engaged the services of persons or agents, not part of the permanent staff of ONS, to undertake parts of the census operation. For the 2001 Census, for example, the following areas of work were contracted out for the first time:

- the administration of the field staff payment

- the management of a call centre to run a Census helpline

- the collection of completed census forms via a postal service

- the capture and coding of census data in electronic format; and

- the production of the archival records.

In its report to the Public Accounts Committee ${ }^{4}$, the National Audit Office (NAO) noted that outsourcing helped ONS to introduce some important innovations to deliver the 2001 Census. The value of ONS doing so again is that external suppliers bring with them considerable technical experience and expertise which would otherwise be unavailable to Census takers, and allows ONS to focus on its main task of carrying out the census rather than developing in-house procedures and skills that are not part of its core competencies. Furthermore, the 10-year cycle for the Census, the short processing timetable and extensive data systems required mean that outsourcing provides efficiencies and value for money.

However, the NAO also noted a number of deficiencies in the management of the procurement process and made a number of recommendations on the arrangements for procuring services for future census operations.

As a result, ONS is again contracting out a number of services as a major element in ensuring a value-for-money Census in 2011. Following a lengthy and rigorous tendering and procurement process ONS announced in August 2008 that Lockheed Martin UK had been selected as the winning bidder for the main data capture and coding activities.

Other providers have been appointed after similar procurement exercises to carry out additional and complementary services. In addition to all the services that were outsourced in the 2001 Census, the several procurements cover:

- the recruitment and training of field staff

- the delivery of forms via the postal service 
- questionnaire/form-tracking systems

- the translation, printing and distribution of non-questionnaire material

- the provision of online response facilities for form completion and public self-help, and

- the publicity and advertising campaigns.

\section{Coverage and data quality}

Ultimately, the success of the Census relies heavily on its accuracy and how well it can estimate the population and its characteristics. The Census will never count every single household and individual, but quality is at the heart of planning the 2011 Census, and many of the innovations that were trialled in the 2007 Census Test $^{6}$ were about improving the quality of census processes and, thus, the data.

A Census, by its nature, is designed to cover the whole population, but errors inevitably arise. A good census design will recognise this and take account of them. For example, the Address Register - no matter how up to date - may fail to record all residential accommodation in an area at the time of the Census; field staff may fail to identify all households within a multi-occupied dwelling; not all members of a recorded household may be included; non-response bias occurs when people do not complete a census form or do not answer all the questions; and there may also be system or processing errors.

The improvements which are being introduced for the 2011 Census have been designed to minimise these errors; for example:

- the creation of an up-to-date Address Register agreed with stakeholders, together with a form-tracking system functioning in real time, will provide a reference to ensure that questionnaires are delivered to, and returns collected from, all residential addresses and that monitoring of return rates can be done in real time

- the re-design of the Census questionnaire and the facility to return it online will make it easier for respondents to complete the form and for ONS to process the data; and

- the focusing of field resources in areas of lower response is aimed at improving the overall coverage.

Non-response or under-enumeration is the most significant error. While the estimated overall undercoverage in the 2001 Census ( 6 per cent in Great Britain) was small compared with national government surveys, it was greater than in 1991 (4 per cent), reflecting an international pattern of increasing non-response in the Census. But of more significance was its variation across population subgroups and different parts of the country.

The concept of 'data quality' can be described as 'fitness for purpose' in terms of user needs. The goals for 2011 are to maximise the overall quality of data and to minimise the differences in quality between areas. A necessary process of coverage assessment and adjustment is undertaken to provide accurate national and sub national estimates of the population. In the 2001 Census, this process was called the One Number Census, which adjusted the results of the Census to take account of people who were missed. For 2011, a similar approach will be undertaken but with developments focusing on a number of areas to improve the method.

The strategy is relatively straightforward. A focused post-enumeration survey - the Census Coverage Survey (CCS) - will be employed to measure under-enumeration by undertaking a separate enumeration of a sample of areas over a three to four-week period starting six weeks after the Census itself. The survey will take the form of a short doorstep interview to check on the coverage of households and people within households, and to collect basic demographic characteristics (such as age, sex, marital status, ethnic group and economic activity).
The results of the CCS will then be matched, at the individual level, to the corresponding 2011 Census data, identifying the number and characteristics of those missed in the Census. The combined Census and CCS information, along with statistical models, will be used to produce a consistent set of census-based estimates, which will form the new base for the series of annual mid-year population estimates for local and health authorities.

A fuller description of the strategy to assess undercoverage and to adjust the census results accordingly is given in Population Trends $127^{7}$. This approach will develop and improve the methodology adopted for the 2001 Census that was widely welcomed by users ${ }^{8,9}$. In particular, the intention to collect information on visitors and second residences, in order to improve understanding of changing patterns of usual residency, will tend to complicate coverage assessment. For example, through matching visitors to Census and CCS records, additional information may be available to help identify residents who were recorded neither in the Census nor in the CCS. Furthermore, matching information from administrative sources to the Census so as to better inform the assessment of coverage (and quality) is being considered. Matching the Census database to itself, particularly where people give details of second addresses, is also being considered to assess over-count. The practicability of matching and the levels of accuracy achievable by this are still being assessed. These will inform the final design of the Coverage Survey and adjustment process.

Quality assurance processes will be in place to carry out checks and, where necessary, to make corrections designed to improve the quality of Census data and to ensure that the overall totals are plausible. Quality assuring the results of the 2011 Census will be done throughout the process to ensure:

- that changes made within each of the processes are robust and do not introduce systematic error; and

- that the national and sub-national (in particular, local authority) estimates are plausible when compared with data from administrative sources and demographic comparators.

A Quality Report will be produced to accompany and support the release of the main statistical outputs.

After the 2001 Census, work on the mid-year population estimates identified the need for further adjustments to the estimates in a small number of areas. The difficulty was that these issues were not resolved until 2004. For the 2011 Census, ONS recognises that it will be important to build in improvements that will prevent these problems occurring or, if they do, resolve them more speedily, including taking account of other sources and local knowledge as appropriate. This involves working with key stakeholders (in particular, local authorities) in advance of the Census - an engagement that is already well under way.

\section{Protecting confidentiality}

The importance of achieving maximum coverage in the Census necessitates that public participation should be mandatory. This in turn puts an obligation on ONS to ensure that the information, sometimes sensitive information, given in confidence in the Census is treated with the strictest confidentiality. The statutory requirement to provide personal census information is prescribed by the provisions of the Census Act 1920 and in the Order and Regulations made under the Act. In return, the Act - now strengthened by the confidentiality provisions of the Statistics and Registration Service Act 2007 - also imposes strict requirements on ONS to protect the confidentiality of any such information collected.

The public must be confident that their personal census records will be held securely. So, as in previous censuses, assurances will be given that 
all the information provided will be treated in strictest confidence by the Census Office. There is a well-established reputation of maintaining census confidentiality which ONS intends to uphold.

The information collected in the 2011 Census will be used solely for the production of statistics and statistical research. Usage will comply fully with the Census Act, the Statistics and Registration Service Act and the requirements of data protection and freedom of information legislation. There are legal penalties for the unlawful disclosure of personal information collected in the census.

ONS will ensure that Government-wide standards relating to information risk management and data security are met. The following principles will govern the treatment of the information given in the Census returns:

(i) Only persons under the management and/or control of the UK Statistics Authority including those agents acting, or providing services, on its behalf for the purpose of the Census, and researchers approved under the provisions of the Statistics and Registration Service Act 2007, will have access to personal census information.

(ii) In most cases one questionnaire will cover all members of the household and information will be returned by post; but, if they wish, people will be able to give personal information on a separate questionnaire, or via a secure online facility, in a way that will not reveal it to others in their household or establishment, or to the Enumerator.

(iii) All members of the Census organisation and outside agents providing services to the UK Statistics Authority will be given strict instructions, and will be required to sign undertakings in the form of declarations, to ensure their awareness of their statutory confidentiality obligations. They will be liable to prosecution for any breaches of the law.

(iv) The physical security of personal Census information held in the Census Office, by field staff or by authorised agents will be strictly enforced. All sites processing Census data will have continuous security arrangements in place including access control, CCTV, security guards, intruder alarms and ONS staff to monitor suppliers, and independent checks, by an accredited UK security organisation, of both physical and electronic security will be carried out.

(v) All relevant UK Government Security requirements will be adhered to in all areas to ensure the overall security of the IT systems and the associated processes and procedures. Such measures taken will conform entirely to specific mandatory requirements in the procedures for the handling of personal data within Government. The computer systems handling Census data will have strict safeguards to prevent unauthorised access.

(vi) The security and confidentiality arrangements covering the collection and processing of census forms will be subject to an independent review.

The 2011 Census White Paper ${ }^{2}$ noted in particular that UK Statistics Authority is satisfied that ONS has fully addressed concerns about the security and confidentiality of Census data arising from the involvement of Lockheed Martin UK. In essence this confirms that neither Lockheed Martin UK Ltd nor any Lockheed Martin employee will have access to personal Census data. All Census data is owned by ONS and will be processed in the UK. Lockheed Martin UK will be acting as the prime contractor and will develop the systems to be used to handle and process the Census data, but access to the data itself will be restricted only to a consortium of subcontractors who are based in the UK and either UK or EU owned and will be protected to the standards required by the Data Protection Act 1998.

There will also be systematic modification of the data in the preparation of the results of the Census in order to preserve statistical confidentiality.
In particular precautions will be taken so that published tabulations and abstracts of statistical data are in line with both the Statistics and Registration Service Act 2007 and the National Statistics Code of Practice. Special precautions may apply particularly to statistical outputs for small areas. Measures to ensure disclosure control (that is, to prevent the release of statistical information that identifies characteristics about an individual person or household) will include some, or all, of the following procedures:

- restricting the number of output categories into which a variable may be classified, such as aggregated age groups

- where the number of people or households in an area falls below a minimum threshold, the statistical output - except for basic headcounts - will be amalgamated with that for a sufficiently large enough neighbouring area; and/or

- modifying some of the data before the statistics are released through one or more of a variety of means such as record swapping, overimputation and some form of cell perturbation.

The National Statistician, together with the Registrars General for Scotland and Northern Ireland, have published a joint agreement to adopt a common statistical disclosure control policy as part of the move towards seeking harmonised statistical outputs from the 2011 Census across the $\mathrm{UK}^{10}$.

The key strength of the Census is its completeness of coverage and its ability to generate statistics about very small areas and groups of people (as is necessary to ensure that public policies take account of the needs of local communities when formulating policy). Particular care must therefore be taken to balance the need to ensure complete statistical confidentiality against damaging the utility of the data. Taking account of the recommendation of the Treasury Select Committee ${ }^{5}$ to review the mechanism to protect statistical confidentiality the National Statistician and the Registrars General have taken steps to ensure that no statistics will be produced that allow the identification of an individual (or information about an individual) with a high degree of confidence.

In a Census context, where thousands of cross-tabulations are generated from one database, statistical confidentiality can be achieved by introducing uncertainty about the true value of small cells. In order to meet the agreed interpretation of the Code of Practice, the three UK Census Offices have agreed that small counts could be included in publicly disseminated Census data provided that:

- uncertainty as to whether or not the small cell is a true value has been systematically created; and

- creating that uncertainty does not significantly damage the data.

The exact threshold of uncertainty required has not yet been decided. The National Statistican and the Registrars General will make this judgement, in consultation with users and other experts including the Information Commissioner, at a later stage within the context of results from research into the balance of protection afforded, and damage caused, by various disclosure control methodologies. The research into this is expected to be complete around mid-2009 and, following further consultation with users, a UK statistical disclosure control strategy for tabular outputs will be finalised later this summer, and reported in Population Trends in due course.

\section{Disseminating the results}

In disseminating the results of the Census much emphasis will be put on responsiveness to users' requirements on content, format and means of access, and on high standards in the production of statistics. ONS have started a programme of user consultation to ensure that outputs should be in such a form as to meet the changing requirements of users, but 
anticipates that there is likely to be a continued requirement for national, regional and local authority summaries, and for reports on key findings on particular topics. The resulting dissemination strategy will reflect any requirement for outputs to be made available in a range of media to provide for ease of access to the user and the general public alike. ONS will, together with GROS and NISRA, also ensure that the UK's obligations to prepare those outputs required by Eurostat under recent EU census legislation ${ }^{11}$, are met.

ONS proposes that all standard outputs would be publicly accessible online, and free of charge, from the National Statistics website.

\section{Summary}

The design for the 2011 Census in England and Wales includes a number of methodological and operational features and innovations aimed at improving the quality of the information collected, and reported, on the resident population. These include: the delivery of Census forms to the majority of households by post; the facility to return the completed information online; the development of a central address register to facilitate improved form delivery and field management; the outsourcing of the recruitment, training and payment of field staff to specialist service providers; closer liaison with local authorities to help tailor the field operation to meet local conditions; a strategy to improve coverage assessment and adjustment; and making publicly available all standard outputs online and free of charge from the National Statistics website subject to an agreed statistical disclosure control process.

\section{References}

1 White I and McLaren E (2008) 'The 2011 Census taking shape: the selection of topics and questions'. Population Trends 135, pp 8-19. Palgrave Macmillan. ISBN 978-0-230-57716-9.
2 Cabinet Office (2008) Helping to shape tomorrow. Cm 7513. The Stationery Office. ISBN 978-0-10-175132-2.

3 National Audit Office (2002) Outsourcing the 2001 Census. Report by the Comptroller and Auditor General. HC 1211, Session 2001/02. The Stationery Office.

4 Office for National Statistics (2008) 2007 Census Test Evaluation key lessons learned. Census Advisory Group Paper CAG(08)01. Available at: www.ons.gov.uk/census/2011-census/consultations/ user-adv-groups/census-adv-groups/index.html

5 House of Commons Treasury Committee (2002) The 2001 Census in England and Wales. First Report of the Session 2001-02. HC 310. The Stationery Office.

6 Benton P et al (2006) 'The 2007 Census Test: a major step towards the 2011 Census'. Population Trends 126 pp 16-28. Palgrave Macmillan. ISBN 0-230-00321-4.

7 Abbott, O (2007) '2011 Census coverage assessment and adjustment strategy'. Population Trends 127, pp 7-13. Palgrave Macmillan. ISBN 978-0-230-52612-9.

8 Statistics Commission (2003) Census and population estimates and the 2001 Census in Westminster: final report. Report no. 22. Statistics Commission.

9 Local Government Association (2003) 2001 One Number Census and its quality assurance: a review. LGA Research Briefing 6.03. Local Government Association.

10 Office for National Statistics, General Register Office for Scotland, Northern Ireland Statistics and Research Agency (2006) The conduct of the 2011 Censuses in the United Kingdom: statement of agreement of the National Statistician and the Registrars General for Scotland and Northern Ireland. Available at: www.ons.gov.uk/census/2011-census/2011-censusproject/index.html

11 Official Journal of the European Union (2008) Regulation (EC) No 763/2008 of the European Parliament and of the Council of 9 July 2008 on population and housing censuses. OJEU, 13 August 2008. 